\title{
Modifications and Additions to the Pediatric and Adult Mathematical Phantoms
}

\author{
J. M. L. Hwang \\ R. L. Shoup \\ J. W. Poston
}




\section{DISCLAIMER}

This report was prepared as an account of work sponsored by an agency of the United States Government. Neither the United States Government nor any agency Thereof, nor any of their employees, makes any warranty, express or implied, or assumes any legal liability or responsibility for the accuracy, completeness, or usefulness of any information, apparatus, product, or process disclosed, or represents that its use would not infringe privately owned rights. Reference herein to any specific commercial product, process, or service by trade name, trademark, manufacturer, or otherwise does not necessarily constitute or imply its endorsement, recommendation, or favoring by the United States Government or any agency thereof. The views and opinions of authors expressed herein do not necessarily state or reflect those of the United States Government or any agency thereof. 


\section{DISCLAIMER}

Portions of this document may be illegible in electronic image products. Images are produced from the best available original document. 
Printed in the United States of America: Available from

National Technical Information Service

U.S. Deparituenll ur Cummerce

5285 Port Royal Road, Springfield, Virginia 22161

Price: Printed Copy $\$ 4.00$; Microfiche $\$ 2.25$

This report was prepared as an account of work sponsored by the United States Government. Neither the United States nor the Energy Research and Development Administration/United States Nuclear Regulatory Commission, nor any of their employees, nor any of their contractors, subcontractors, or their employees, makes any warranty, express or implied, or assumes any legal liability or responsibility for the accuracy, completeness or usefulness of any information, apparatus, product or process disclosed, or represents that its use would not infringe privately owned rights 
ORNL/TM-5454

Contract No. W-7405-eng-26

HEALTH PHYSICS DIVISION

MODIFICATIONS AND ADDITIONS TO THE

PEDIATRIC AND ADULT MATHEMATICAL

PHANTOMS

\section{SEPTEMBER 1976}

J. M. L. Hwang, R. L. Shoup and J. W. Poston

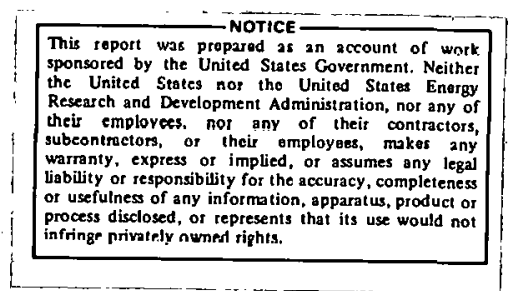

NOTICE This document contains information of a preliminary nature and was prepared primerlly for internal use at the Oak Ridge National Laboratory. It is subject to revision or correction and therefore does not represent a final report.

OAK RIDGF: NATIONAL LABORATORY

Oak Ridge, Tennessee 37830

operated by

UNION CARBIDE CORPORATION

for

ENERGY RESEARCH AND DEVELOPMENT ADMINISTRATION

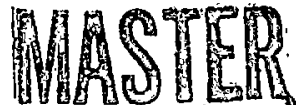

OT $K-2405-E N G-26$ N OF THIS DOCUMENT IS UNLIMITED

oy 


\section{THIS PAGE}

\section{WAS INTENTIONALLY \\ LEFT BLANK}


TABLE OF CONTENTS

INTRODUCTION . . . . . . . . . . . . . . . . . . . . . . 1

MODIFICATION OF THE ONE YEAR-OLD PHANTOM . . . . . . . . . . . . . 3

Mandible . . . . . . . . . . . . . . . . 5

Cranium . . . . . . . . . . . . . . . . . 5

Brain . . . . . . . . . . . . . . . . . 6

Thyroid . . . . . . . . . . . . . . . . . 6

Salivary Glands . . . . . . . . . . . . . . . . 6

-Parotid Glands . . . . . . . . . . . . . . . 6

-Submaxillary Glands . . . . . . . . . . . . . . . . . 7

-Sublịngual Glands . . . . . . . . . . . . . . . . . 7

Gall Bladder . . . . . . . . . . . . . . . . . 8

MODIFICATION OF THE FIVE YEAR-OLD PHANTOM

Mandible . . . . . . . . . . . . . . . . 9

Cranium . . . . . . . . . . . . . . . . . . 9

Brain ..................... 10

Thyroid . . . . . . . . . . . . . . . . . . 10

Salivary Glands . . . . . . . . . . . . . . . . . Il

-Parotid Glands . . . . . . . . . . . . . . . . . . 11

-Submaxillary Glands . . . . . . . . . . . . . . . . 11

-siblingual Glands . . . . . . . . . . . . . . . . . 12

Gall Bladder . . . . . . . . . . . . . . . . . 12

MODIFICATION OF THE ADULT PHANTOM . . . . . . . . . . . . . . 13

Mandible . . . . . . . . . . . . . . . . . . 13

Cranium ........................ 14

Brain ........................ 14 
Thyroid . . . . . . . . . . . . . . . . . 14 Salivary Glands . . . . . . . . . . . . . . . 15

-Parotid Glands . . . . . . . . . . . . . . . 15

-Submaxillary Glands . . . . . . . . . . . . . . 16

-Sublingual Glands . . . . . . . . . . . . . . . 16

Gall Bladder . . . . . . . . . . . . . . . . . . . 17

REFERENCES . . . . . . . . . . . . . . . . . . . . 18 
LIST OF FIGURES

Fig. $1 \quad Y-Z$ and $X-Z$ Sectional Plots of the Adult Phantom . . . . 2

Fig. 2 Head Section of Phantom Illustrating. Approximate

Location of Salivary Glands. . . . . . . . . . 4 


\section{INTRODUCTION}

Mathematical representations of humans one year, five years, and twenty years (adult) of age have heen modified and are discussed in detail in the following sections. These modifications include the addition of a mandible and salivary glands in the head section and the inclusion of the gall bladder to the trunk region. Originally, these phantoms consisted of 22 internal organs, a skeletal system consisting of ten individual sections and the lungs as reported in ORNL-TM-5293 for the one year and five year old phantoms and MIRD Pamphlet \#5 for the adult. These changes were incorporated into the newborn phantom during its design which are reported in ORNL-TM-5453 and hence are not included in this report.

These mathematical phantoms are undergoing continuous refinement in response to their increasing usefulness in absorbed dose calculations for both external and internal emitters and x-ray procedures. The addition of a gall bladder in the cavity slightly to the left of the liver is useful because this organ is studied by both diagnostic $x$-ray and nuclear medicine procedures. Certain radiopharmaceuticals concentrate in the gall bladier and techniques are needed to calculate the abcorbed dose to the gall bladder wall (Fig. 1).

The head sections are modified to include the facial bones--a mandible and maxilla--and will be referred to as the mandible for simplicity. In the past, the skull was designed to be thicker at its 

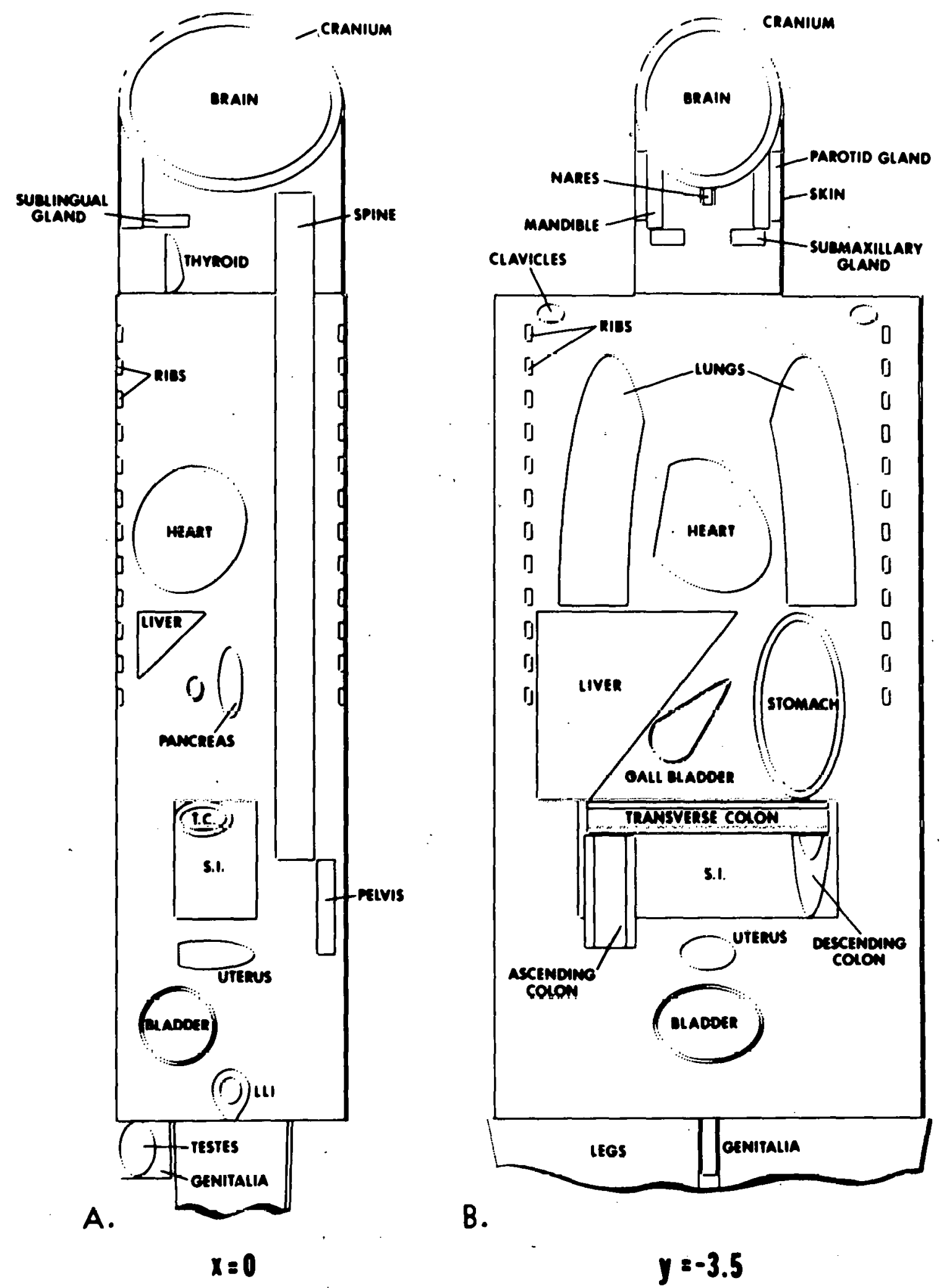

Figure 1. $Y-Z$ and $X-Z$ Sectional Plots of the Adult Phantom. 
base to compensate for the absence of the skeletal mass of the mandible. This precluded the ability of performing dental dosimetry calculations. The skull (cranium) is redesigned to a sherodial shell of constant thickness where the outer spheroid maintains nearly the same mathematical description as the upper hemispheroidal geometry as before. The added mandible is mask-like in shape being placed in the front lower section of the head and with radii slightly less than that of the elliptical shape of the head in order to accommodate the parotid salivary glands (Fig. 2). The submaxillary and sublingual salivary glands are placed in the appropriate positions proximal to the mandible with the thyroid gland being moved slightly back towards the center of the lower head section and in a more natural position. With these head section modifications, absorbed doses to the mandible and salivary glands can be calculated for $x$-rays. The salivary glands are of interest because of the manifestations of cancers in these glands which have been attributed to $x$-ray exposures.

Data for gall bladder mandible, and salivary gland shapes, sizes and weights were obtained from the ICRP Task Group Report on Reference $\mathrm{Man}^{1}$ and anatomical references. ${ }^{2,3}$ The remaining sections describe, mathematically, these changes to the one year, five year, and twenty year-old phantoms respectively.

MODIFICATION OF THE ONE YEAR-OLD PHANTOM

Mudification of the head section and the addition of two new organs-salivary glands and gall bladder-to the one year-old phantom are described below. 
ORNL-DWG 76-1947

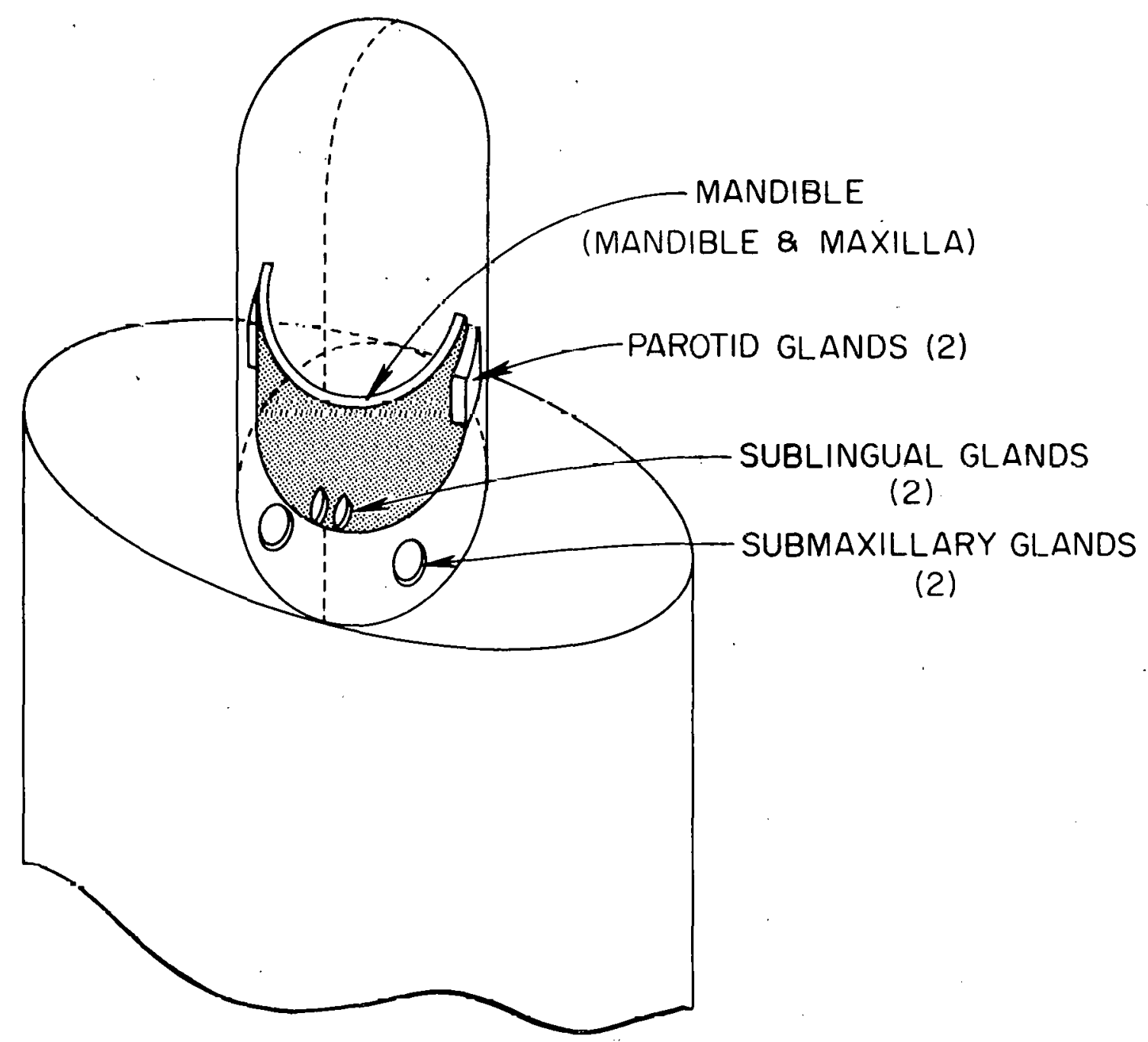

Figure 2. Head Section of Phantom Illustrating Approximate Location of Salivary Glands: 
Mandible. The mandible is a portion of the volume between two concentric elliptical cylinders. The upper rear portion of these cylinders intersect the cranium and brain, and this volume is subtracted off. The mandible is described by

$$
\begin{gathered}
\left(\frac{X}{4.5}\right)^{2}+\left(\frac{Y}{6.4}\right)^{2} \geq 1 \\
\left(\frac{X}{5.6}\right)^{2}+\left(\frac{Y}{7.8}\right)^{2} \leq 1 \\
Y \leqq 0 \\
34.5 \leq Z \leqq 42.3
\end{gathered}
$$

and

$$
\left(\frac{X}{6.6}\right)^{2}+\left(\frac{y}{7.8}\right)^{2}+\left(\frac{z-43.1}{6.3}\right)^{2}, \geq 1
$$

The total volume of the mandible is $196.71 \mathrm{~cm}^{3}$, and the mass is $135.4 \mathrm{~g}$.

Cranium. The cranium is the volume between two concentric ellipsoids defined by

$$
\begin{aligned}
& \left(\frac{X}{5.9}\right)^{2}+\left(\frac{Y}{7.1}\right)^{2}+\left(\frac{Z-43.1}{5.5}\right)^{2} \geqq 1 \\
& \left(\frac{X}{6.6}\right)^{2}+\left(\frac{Y}{7.8}\right)^{2}+\left(\frac{Z-43.1}{6.3}\right)^{2} \leqq 1 .
\end{aligned}
$$

The total volume of the cranium is $393.5 \mathrm{~cm}^{3}$, and the mass is $550.8 \mathrm{~g}$.

The total volume of the skeletal parts of the head section is $490.16 \mathrm{~cm}^{3}$, and the mass is $686.22 \mathrm{~g}$. 
Brain. The brain is an ellipsoid given by

$$
\left(\frac{X}{5.9}\right)^{2}+\left(\frac{Y}{7.1}\right)^{2}+\left(\frac{Z-43.1}{5.5}\right)^{2} \leqq 1
$$

and the volume is $965 \mathrm{~cm}^{3}$, and the mass is $993 \mathrm{~g}$.

Thyroid. The lobes of the thyroid lie between two concentric cylinders and are formed by a cutting surface. The expressions for this orgun ure

$$
\begin{gathered}
X^{2}+(Y+2.8)^{2} \stackrel{\leftrightarrows}{=}(1.6)^{2} \\
X^{2}+(Y+2.8)^{2} \geqq(1.4)^{2} \\
Y+2.8 \leqq 0 \\
32 \leqq Z \leqq 35.6 \\
{[(Y+2.8)-|X|]^{2} \geqq 2\left[X^{2}+(Y+2.8)^{2}\right] \tau^{2},}
\end{gathered}
$$

in which

$$
\tau=\frac{5}{9}(\sqrt{2}-2)(z-32)+1 \text { for } 0 \leqq z-32 \leqq \frac{9}{10}
$$

and

$$
\tau=\frac{5(2-\sqrt{2})}{27}(z-32)+\frac{2 \sqrt{2}-1}{3} \text { for } \frac{9}{10} \leqq z-32 \leqq \frac{18}{5}
$$

The volume is $2.26 \mathrm{~cm}^{3}$ and the mass is $2.38 \mathrm{~g}$.

Siglivary Glands. The salivary glands cunsish of thret pairs of glands located proximal to the mandible within the head section. These three pairs of glands are described below:

-Parotid Glands. These glands are triangular shaped and lie between the skin and mandible on the right and left sides of the head. 
Their volumes are described by sections of two concentric elliptical cylinders cut by an elliptical surface in the $Y-Z$ plane. These parotid glands are given by the equations

$$
\begin{gathered}
\left(\frac{Y+2.6}{2.6}\right)^{2}+\left(\frac{Z-38.5}{3.6}\right)^{2} \leqq 1 \\
-2.6 \leqq Y \leqq 0 \\
34.9 \leqq Z \leqq 38.5 \\
\left(\frac{X}{5.6}\right)^{2}+\left(\frac{Y}{7.8}\right)^{2} \geqq 1 \\
\left(\frac{X}{6.6}\right)^{2}+\left(\frac{Y}{7.8}\right)^{2} \leqq 1 .
\end{gathered}
$$

The total volume of parotid glands is $14.7 \mathrm{~cm}^{3}$ and the mass is $15.3 \mathrm{~g}$.

-Submaxillary Glands. These glands are elliptical disks which are located immediately below and towards the front part of the mandible. They lie symmetrically on the right and left sides of $x$-axis. They are described as:

$$
\left( \pm \frac{X-3.6}{1.1}\right)^{2}+\left(\frac{Y+3.8}{1.2}\right)^{2} \leq 1
$$

and

$$
33.5 \leqq z \leqq 34.3
$$

the volume of both submaxillary glands is $6.63 \mathrm{~cm}^{3}$, and the mass is $6.9 \mathrm{~g}$.

-Sublingual Glands. These glands are elliptical disks and are located interior to and near the bottom of the mandible. They lie 
symmetrically on the left and right sides of the $X$-axis. They are. given by:

$$
\left( \pm \frac{X-1.2}{0.3}\right)^{2}+\left(\frac{Y+4.7}{1.4}\right)^{2} \leq 1
$$

and

$$
35.65 \leqq z \leqq 36.35
$$

The volume of both sublingual glands is $1.84 \mathrm{~cm}^{3}$ and the mass is $1.93 \mathrm{~g}$.

Gall Bladder. The gall bladder is defined by the frustrum of a cone capped with a hemisphere. A rotation and translation are then effected. The gall bladder is represented by

$$
\begin{aligned}
& X_{1}=0.8516(X-0.1)+0.4226(Y+1.8)-0.3099(Z-12.7) \\
& Y_{1}=-0.3971(X-0.1)+0.9063(Y+1.8)+0.1445(Z-12.7) \\
& Z_{1}=0.342(X-0.1)+0.9396(Z-12.7)
\end{aligned}
$$

$i t z_{1}<0$

$$
\begin{aligned}
& x_{1}^{2}+y_{1}^{2}+z_{1}^{2} \leqq(1.3)^{2} \\
& x_{1}^{2}+y_{1}^{2}+z_{1}^{2} \geqq(1.2)^{2}
\end{aligned}
$$

if $0 \leqq Z_{1} \leqq 2.6$

$$
\begin{aligned}
& X_{1}^{2}+Y_{1}^{2} \leq\left(1.3-\frac{1.1}{2.6} Z_{1}\right)^{2} \\
& X_{1}^{2}+Y_{1}^{2} \geqq\left(1.2-\frac{1.1}{2.6} Z_{1}\right)^{2} .
\end{aligned}
$$


The volume is $2.1 \mathrm{~cm}^{3}$, and the mass is $2.16 \mathrm{~g}$. The contents have a volume of $7.9 \mathrm{~cm}^{3}$ and a mass of $8.1 \mathrm{~g}$. This represents a moderately full gall bladder.

\section{MODIFICATION OF THE FIVE YEAR-OLD PHANTOM}

Modification of the head section and the addition of two new organssalivary glands and gall bladder-to the five year-old phantom are described below:

Mandible. The mandible is a portion of the volume between two concentric elliptical cylinders. The upper rear portion of these cylinders intersect the cranium and brain and this volume is subtracted off. The mandible is described by:

$$
\begin{gathered}
\left(\frac{X}{4.5}\right)^{2}+\left(\frac{Y}{7.2}\right)^{2} \geqq 1 \\
\left(\frac{X}{5.6}\right)^{2}+\left(\frac{Y}{8.6}\right)^{2} \leqq 1 \\
Y \leqq 0 \\
45 \leqq Z \leqq 53
\end{gathered}
$$

and

$$
\left(\frac{X}{6.6}\right)^{2}+\left(\frac{Y}{8.6}\right)^{2}+\left(\frac{Z-54.6}{6.5}\right)^{2} \geqq 1 .
$$

The total volume of the mandible is $1.36 .4 \mathrm{~cm}^{3}$, and the mass is $190,9 \mathrm{~g}$.

Cranium. The cranium is the volume between two concentric ellipsoids defined by 


$$
\begin{aligned}
& \left(\frac{X}{5.9}\right)^{2}+\left(\frac{Y}{7.9}\right)^{2}+\left(\frac{Z-54.6}{5.87}\right)^{2} \geqq 1 \\
& \left(\frac{X}{6.6}\right)^{2}+\left(\frac{Y}{8.6}\right)^{2}+\left(\frac{Z-54.6}{6.5}\right)^{2} \geqq 1 .
\end{aligned}
$$

The total volume of the cranium is $399.3 \mathrm{~cm}^{3}$, and the mass is $559 \mathrm{~g}$.

The total volume of the skeletal parts of the head section is $535.76 \mathrm{~cm}^{3}$, and the mass is $750 \mathrm{~g}$.

Braill. The braill is all ellipsuid givell by

$$
\left(\frac{X}{5.9}\right)^{2}+\left(\frac{Y}{7.9}\right)^{2}+\left(\frac{Z-54.6}{5.87}\right)^{2} \leq 1
$$

and the volume is $1146 \mathrm{~cm}^{3}$, and the mass is $1179 \mathrm{~g}$.

Thyroid. The lobes of the thyroid lie between two concentric cylinders and are formed by a cutting surface. The expressions for this organ are

$$
\begin{gathered}
X^{2}+(Y+3.3)^{2} \leqq(1.9)^{2} \\
X^{2}+(Y+3.3)^{2} \geqq(1.6)^{2} \\
, Y+3.3 \leqq 0 \\
42 \leqq Z \leqq 46.2 \\
{[(Y+3.3)-|X|]^{2} \geqq 2\left[X^{2}+(Y+3.3)^{2}\right] \tau^{2}}
\end{gathered}
$$

in which

$$
\tau=\frac{10}{21}(\sqrt{2}-2)(Z-42)+1 \text { for } 0 \leqq z-42 \leqq 1.05
$$


and

$$
\tau=\frac{10}{63}(2-\sqrt{2})(z-42)+\frac{2 \sqrt{2}-1}{3} \text { for } \quad 1.05 \leqq z-42 \leqq 4.2 .
$$

The volume is $4.62 \mathrm{~cm}^{3}$ and the mass is. $4.85 \mathrm{~g}$.

Salivary Glands. The salivary glands consist of three pairs of glands located proximal to the mandible within the head section. These three pairs of glands are described below.

-Parotid Glands. These glands are triangular shaped and lie between the skin and mandible on the right and left sides of the head. Their volumes are described by sections of two concentric elliptical cylinders cut by an elliptical surface in the $Y-Z$ plane. These parotid glands are given by the equations:

$$
\begin{gathered}
\left(\frac{Y+3.2}{3.2}\right)^{2}+\left(\frac{Z-49.5}{4.4}\right)^{2} \leqq 1 \\
-3.2 \leqq Y \leqq 0 \\
45.4 \leqq Z \leqq 49.8 \\
\left(\frac{X}{5.6}\right)^{2}+\left(\frac{Y}{8.6}\right)^{2} \leqq 1 \\
\left(\frac{X}{6.6}\right)^{2}+\left(\frac{Y}{8.6}\right)^{2} \leqq 1
\end{gathered}
$$

The total volume of the parotid glands is $22.1 \mathrm{~cm}^{3}$ and the mass is $23 \mathrm{~g}$. -Submaxillary Glands. These glands are elliptical disks which are located immediately below and towards the front part of the mandible. 
They lie symmetrically on the right and left sides of the $x$-axis. They are described as:

$$
\left( \pm \frac{X-3.6}{1.1}\right)^{2}+\left(\frac{Y+4.3}{1.3}\right)^{2} \leq 1
$$

and

$$
44.1 \leqq z \leqq 44.9
$$

The volume of both submaxillary $\mathrm{glands}$ is $7.18 \mathrm{~cm}^{3}$, and the mass is $7.5 \mathrm{~g}$.

-Sublingual Glands. These glands are elliptical disks and are located interior to and near the bottom of the mandible. They lie symmetrically on the left and right sides of the X-axis. They are given by :

$$
\left( \pm \frac{X-1.3}{0.4}\right)^{2}+\left(\frac{Y+5.1}{1.6}\right)^{2} \leq 1
$$

and

$$
46.3 \leqq z \leqq 47
$$

The volume of both sublingual glands is $2.81 \mathrm{~cm}^{3}$ and the mass is $2.95 \mathrm{~g}$.

Gall Bladder. The gall bladder is defined by the frustrum of a cone capped with a hemisphere. A rotation and translation are then effected. 'l'he gall bladder is represented by

$$
\begin{aligned}
& X_{1}=0.8516(X+0.3)+0.1226(Y+2.3)-0.3099(Z-17.5) \\
& Y_{1}=-0.3971(X+0.3)+0.9063(Y+2.3)+0.1445(Z-17.5) \\
& Z_{1}=0.342(X+0.3)+0.0306(Z-17.5)
\end{aligned}
$$


if $z_{1}<0$

$$
\begin{aligned}
& x_{1}^{2}+\dot{y}_{1}^{2}+z_{1}^{2} \leq(1.8)^{2} \\
& x_{1}^{2}+y_{1}^{2}+z_{1}^{2} \geq(1.7)^{2}
\end{aligned}
$$

if $0 \leqq z_{1} \leqq 2.6$

$$
\begin{aligned}
& x_{1}^{2}+Y_{1}^{2} \leqq\left(1.8-0.31 z_{1}\right)^{2} \\
& x_{1}^{2}+Y_{1}^{2} \geqq\left(1.7-0.31 z_{1}\right)^{2} .
\end{aligned}
$$

The volume is $4.98 \mathrm{~cm}^{3}$, and the mass is $5.13 \mathrm{~g}$. The contents have a volume of $26.87 \mathrm{~cm}^{3}$ and a.mass of $27.56 \mathrm{~g}$. This represents a moderately full gall bladder.

MODIFICATION OF THE ADULT PHANTOM

Modification of the head section and the addition of two new organssalivary glands and gall bladder-to the adult phantom are described below.

Mandible. The mandible is a portion of the volume between two concentric elliptical cylinders. The upper rear portion of these cylinders intersect the cranium and brain and this volume is subtracted off. The mandible is described by:

$$
\left(\frac{X}{4.4}\right)^{2}+\left(\frac{Y}{8.0}\right)^{2} \geqq 1
$$




$$
\begin{gathered}
\left(\frac{X}{5.7}\right)^{2}+\left(\frac{Y}{9.8}\right)^{2} \leqq 1 \\
Y \leqq 0
\end{gathered}
$$

$$
75.5 \leqq Z \leqq 85.1
$$

and

$$
\left(\frac{X}{6.8}\right)^{2}+\left(\frac{Y}{9.8}\right)^{2}+\left(\frac{Z-86.1}{7.7}\right)^{2} \geq 1 .
$$

The total volume of the mandible is $162.4 \mathrm{~cm}^{3}$, and the mass is $227.4 \mathrm{~g}$.

Cranium. The cranium is the volume between two concentric ellipsolds defined by

$$
\begin{aligned}
& \left(\frac{X}{5.9}\right)^{2}+\left(\frac{Y}{8.9}\right)^{2}+\left(\frac{Z-86.1}{6.68}\right)^{2} \geqq 1 . \\
& \left(\frac{X}{6.8}\right)^{2}+\left(\frac{Y}{9.8}\right)^{2}+\left(\frac{Z-86.1}{7.7}\right)^{2} \leqq 1 .
\end{aligned}
$$

The total volume of the cranium is $608 \mathrm{~cm}^{3}$, and the mass is $952 \mathrm{~g}$.

Brain. The brain is an ellipsoid given by

$$
\left(\frac{X}{5.9}\right)^{2}+\left(\frac{Y}{8.9}\right)^{2}+\left(\frac{Z-86.1}{6.68}\right)^{2} \leq 1
$$

and the volume is $1409.28 \mathrm{~cm}^{3}$, and the mass is $1450.29 \mathrm{~g}$.

Thyroid. The lobes of the thyroid lic between two concentric cylinders and are formed by a cutting surface. The expressions for this organ are 


$$
\begin{gathered}
X^{2}+(Y+4)^{2} \leqq(2.2)^{2} \\
X^{2}+(Y+4)^{2} \geqq 1^{2} \\
Y+4 \leq 0 \\
70 \leqq Z \leqq 75 \\
{[(Y+4)-|X|]^{2} \geqq 2\left[X^{2}+(Y+4)^{2}\right] \tau^{2}}
\end{gathered}
$$

in which

$$
\tau=\frac{2(\sqrt{2}-2)}{5}(Z-70)+1 \text { for } 0 \leqq Z-70 \leqq \frac{5}{4}
$$

in which

$$
\tau=\frac{2(2-\sqrt{2})}{15}(z-70)+\frac{2 \sqrt{2}-1}{3} \text { for } \frac{5}{4}<z-70 \leqq 5 .
$$

The volume is $19.89 \mathrm{~cm}^{3}$ and the mass is $19.63 \mathrm{~g}$.

Salivary Glands. The salivary glands consist of three pairs of glands located proximal to the mandible within the head section. These three pairs of glands are described below.

-Parotid Glands. These glands are triangular shaped and lie between the skin and mandible on the right and left sides of the head. Their volumes are described by sections of two concentric elliptical cylinders cut by an elliptical surface in the $Y-Z$ plane. These parotid glands are given by:

$$
\begin{gathered}
\left(\frac{Y+4.5}{4.5}\right)^{2}+\left(\frac{Z-82}{6}\right)^{2} \leqq 1 \\
-4.5 \leqq Y \leqq 0
\end{gathered}
$$




$$
\begin{gathered}
76 \leqq Z \leqq 82 \\
\left( \pm \frac{X}{5.7}\right)^{2}+\left(\frac{Y}{9.8}\right)^{2} \geqq 1 \\
\left( \pm \frac{X}{6.8}\right)^{2}+\left(\frac{Y}{9.8}\right)^{2} \leqq 1 .
\end{gathered}
$$

The total volume of parotid glands is $46.65 \mathrm{~cm}^{3}$ and the mass is $48.5 \mathrm{~g}$.

-Submaxillary Glands. These glands are elliptical disks which are located immediately below and towards llie front part of the mandible. They lie symmetrically on the right and left sides of $X$-axis. They are described as

$$
\left( \pm \frac{X-3.5}{1.5}\right)^{2}+\left(\frac{Y+3.9}{1.75}\right)^{2} \leq 1
$$

and

$$
71.1 \leq z \leq 7, .4
$$

the volume of both submaxillary glands is $21.44 \mathrm{~cm}^{3}$, and the mass is $22.38 \mathrm{~g}$.

-Sublingual Glands. These glands are elliptical disks and located interior to and near the bottom of the mandible. They lie symmetrically on the left und riglit sides nf the $X$ axis. They are given hy

$$
\left(\frac{X-1.4}{0.5}\right)^{2}+\left(\frac{Y+5.5}{2}\right)^{2} \leq 1
$$

and

$$
75.6 \leq Z \leq 76.6
$$


The volume of both sublingual glands is $6.28 \mathrm{~cm}^{3}$ and the mass is $6.58 \mathrm{~g}$.

Gall Bladder. The gall bladder is defined by the frustrum of a cone capped with a hemisphere. A rotation and translation are then effected. The gall bladder is represented by

$$
\begin{aligned}
& X_{1}=0.64085(X+3)+0.4226(Y+3)-0.6408(Z-32.2) \\
& Y_{1}=-0.2988(X+3)+0.9063(Y+3)+0.2988(Z-32.2) \\
& Z_{1}=0.7071(X+3)+0.7071(Z-32.2)
\end{aligned}
$$

if $z<0$

$$
\begin{aligned}
& x_{1}^{2}+y_{1}^{2}+z_{1}^{2} \leq(2.12)^{2} \\
& x_{1}^{2}+y_{1}^{2}+z_{1}^{2} \geqq(2.0)^{2}
\end{aligned}
$$

if $0 \leqq Z_{1} \leqq 8$

$$
\begin{gathered}
X_{1}^{2}+Y_{1}^{2} \leq\left(2.12-0.2275 Z_{1}\right)^{2} \\
X_{1}^{2}+Y_{1}^{2} \geqq\left(2-0.225 Z_{1}\right)^{2} .
\end{gathered}
$$

The volume is $9.74 \mathrm{~cm}^{3}$, and the mass is $9.61 \mathrm{~g}$. The contents have a volume of $54 \mathrm{~cm}^{3}$ and a mass of $53.3 \mathrm{~g}$. This represents a moderately full gall bladder. 
REFERENCES .

1. W. S. Snyder, M. J. Cook, E. S. Nasset, L. Karhausen, G. P. Howells, and I. H. Tipton, Report of the Task Group on Reference Man, ICRP Publication No. 23 (1975).

2. J. C. Boileau Grant, Atlas of Anatomy, The Williams \& Wilkins Co,., Baltimore, 1972 .

3. Morris' Human Anatomy, ed. by J. Parsons Schaeffer, McGraw-Hill Book Co., Inc., New York, 1953. 
INTERNAL DISTRIBUTION

1-2. Central Research Libary

3. Document Reference Section

4-6. Laboratory Records Department

7. Laboratory Records, ORNL R. C.

8. ORNL Patent Office

9. Research and Technical Support Div.

10-36. Technical Information Center

37. J. A. Auxier

38. S. R. Bernard

39. M. F. Fair

40. M. R. Ford

41. F. F. Haywood

42. J. L. Hwang
43. D. G. Jacobs

44. T. D. Jones

45. G. D. Kerr

46. S. K. Penny

47-71. J. W. Poston

72. C. R. Richmond

73-87. R. L. Shoup

88. W. S. Snyder

89. P. S. Stansbury

90. S. B. Watson

91. G. G. Warner

92. H. A. Wright

\section{EXTERNAL DISTRIBUTION}

93. S. James Adelstein, Shields Warren Radiology Lab., 50 Binney St., Boston, Mass. 02115.

94. Monte Blau, Roswell Park Memorial Institute, Dept. of Nuclear Medicine, 666 Elm Street, Buffalo, NY 14203.

95. Mones Berman, National Cancer Institute of Health, Building 10, Room 4B-56, Bethesda, MD 20014.

96. C. E. Carter, Division of Biomedical and Environmental Research, ERDA, Washington, D.C. 20545.

97. R. J. Cloutier, ORAU, Oak Ridge, Tennessee 37830.

98. R. D. Cooper, Division of Biomedical and Environmental Research, ERDA, Washington, D.C. 20545.

99. Dr. George Cowper, Atomic Energy of Canada, Ltd., Chalk River, Ontario, Canada.

100. L. J. Deal, Asst. Director of Safety Protection, Division of Operational Safety, ERDA, Washington, D.C. 20545.

101. L. T. Dillman, Department of Physics, Ohio Wesleyan University, Delaware, Ohio 43015.

102. Mrs. Judy Glos, The Society of Nuclear Medicine, 475 Park Avenue South, New York, NY 10016.

103. Alexander Gottschalk, Department of Radiology, Yale University School of Medicine, 333 Cedar Street, New Haven, CT 06510.

104. R. J. Hart, Manager, Oak Ridge Operations.

105. Dr. Marguerite T. Hays, 151, Director of Medical Research Services, Vererans Administration, Department of Medicine and Surgery, Washington, D.C. 20420.

106. R. Eugene Johnston, Dept, of Radiology, N.C.M.H., Division of Nuclear Medicine, University of North Carolina, Chapel Hill, N.C. 27514. 


\section{EXTERNAL DISTRIBUTION (CON'T)}

107. Dr. James Kereiakes, E555 Medical Sciences Building, University of Cincinnati, Cincinnati, Ohio 45267.

108. Katherine A. Lathrop, Frankl in McLean Memorial Research Institute, The Univ. of Chicago, 950 East 59th St., Box 420, Chicago, I11. 60637.

109. Robert Loevinger, Radiation Physics B1dg., Room C210, National Bureau of Standards, Washington, D.C. 20234.

110. John G. McAfee, Division of Nuclear Medicine, Upstate Medical Center, 750 East Adams Street, Syracuse, NY 13210.

111. R. E. McLaughl in, Director, Radiation Physics Division, Health and Safety Laboratory, ERDA, New York Operations Office, 376 Hudson Street, New York, NY 10014.

112. K. Z. Morgan, School of Nuclear Engineering, Georgia Institute uf Technolngy, Atlanta, Georgia 30332.

113. Dr. Peter Paras, Bureau of Radiological Health, Food and Drug Administration, 12720 Twinbrook Parkway, Rockville, MD 20852.

114. E. James Potchen, Office of the Dean, John Hopkins Medical School, 725 N. Wolfe Street, Baltimore, MD 21205.

115. Robert H. Rohrer, Ph.D., Dept. of Physics, Emory University, At1 anta, Georqia 30322.

116. Dr. Marvin Rosenstein, Bureau of Radiological Health, Food and Drug Administration, 12720 Twinbrook Parkway, Rockville, MD 20852.

117. W. W. Schroebel, Division of Biomedical and Environmental Research, ERDA, Washington, D.C. 20545.

118. Dr. Edward M. Smith, Executive Dir., MIRD Committee, 404 Church Ave., Suite 15, Maryville, TN 37801.

119. Dr. L. V. Spencer, Center on Radiation Research, National Bureau Standards, Washington, D.C. 20234.

120. Dr. Betsy J. Stover, Division of Health Affairs, Department of Pharmacology, Swing Bullding, University of North Carolina, Chapel Hill, North Carolina 27514.

121. Dr. Roy L. Thompson, Biology Dept., Pacific Northwest Laboratories, Battelle, Richland, Washington 99352.

122. John C. Villforth, Bureau of Radiological Health, Food and Drug Administration, 12720 Twinbrook Parkway, Rockville, MD 21205.

123. Robert W. Wood, Division of Biomedical and Environmental Research, Radiological Physics and Instrumentation Branch, ERDA, Washington, D.C. 20545. 